\title{
Clinical and Biological Implications of Mutational Spectrum in Acute Myeloid Leukemia of FAB Subtypes M0 and M1
}

\author{
Zhiheng Chenga,b Yifeng Dai ${ }^{\text {c,d }}$ Yifan Pang Yang Jiao $^{f}$ Hongmian Zhao ${ }^{g}$ \\ Sun Wu ${ }^{\text {h }}$ Lingxiu Zhang ${ }^{\text {h }} \quad$ Yuan Zhangh $^{\text {h Xiufeng Wang }}{ }^{\text {h }} \quad$ Lihua Wang $^{\text {h }}$ \\ Dong $\mathrm{Ma}^{\mathrm{h}}$ Tong Qing Ning Hu${ }^{g} \quad$ Yijie Zhang ${ }^{i} \mathrm{Kai}^{\mathrm{H}} \mathrm{u}^{\mathrm{b}}$ Qingyi Zhangh ${ }^{\text {h, }}$ \\ Jinlong Shi ${ }^{\mathrm{a}, \mathrm{k}, \mathrm{l}} \quad$ Lin $\mathrm{Fu}^{\mathrm{b}, \mathrm{g}, \mathrm{m}}$
}

aTranslational Medicine Center, Huaihe Hospital of Henan University, Kaifeng, bepartment of Hematology and Lymphoma Research Center, Peking University, Third Hospital, Beijing, 'Laboratory of Environmental Medicine and Developmental Toxicology, Shantou University Medical College, Shantou, China, IImmunoendocrinology, Division of Medical Biology, Department of Pathology and Medical Biology, University Medical Center Groningen, Groningen, Netherlands, eDepartment of Medicine, William Beaumont Hospital, Royal Oak, USA, fLife Sciences Institute and Innovation Center for Cell Signaling Network, Zhejiang University, Hangzhou, 9Department of Hematology, Huaihe Hospital of Henan University, Kaifeng, " Department of Hematology, The First Affiliated Hospital of Xinxiang Medical University, Weihui, 'Department of Respiratory, Huaihe Hospital of Henan University, Kaifeng, iDepartment of Hematology of Air Force PLA General Hospital, ' ${ }^{2}$ Department of Biomedical Engineering, Chinese PLA General Hospital, Beijing, 'Department of Medical Big Data, Chinese PLA General Hospital,

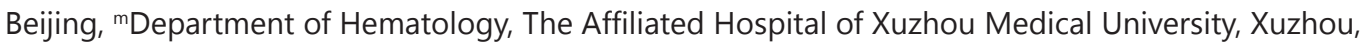
China

\section{Key Words}

Acute myeloid leukemia • M0 and M1 • Next generation sequencing • Mutational spectrum • Prognosis

\begin{abstract}
Background/Aims: Acute myeloid leukemia (AML) of French-American-British (FAB) subtypes $\mathrm{M} 0$ and $\mathrm{M} 1$ are both poorly differentiated $\mathrm{AML}$, but their mutational spectrum and molecular characteristics remain unknown. This study aimed to explore the mutational spectrum and prognostic factors of AML-M0 and M1. Methods: Sixty-five AML patients derived from The Cancer Genome Atlas (TCGA) database were enrolled in this study. Whole-genome sequencing was performed to depict the mutational spectrum of each patient. Clinical characteristics at diagnosis, including peripheral blood (PB) white blood cell counts (WBC), blast percentages in $\mathrm{PB}$ and bone marrow (BM), $F A B$ subtypes and the frequencies of known recurrent genetic mutations were described. Survival was estimated using the Kaplan-Meier methods and log-rank test. Univariate and multivariate Cox proportional hazard models were constructed K. Hu, Q. Zhang, J. Shi, L. Fu contributed equally to this work.


for event-free survival (EFS) and overall survival (OS), using a limited backward elimination procedure. Results: Forty-six patients had more than five recurrent genetic mutations. FLT3 had the highest mutation frequency $(n=20,31 \%)$, followed by NPMI $(n=18,28 \%)$, DNMT3A $(\mathrm{n}=16,25 \%), I D H 1(\mathrm{n}=14,22 \%), I D H 2(\mathrm{n}=12,18 \%), R U N X 1(\mathrm{n}=11,17 \%)$ and TET2 $(\mathrm{n}=7,11 \%)$. Univariate analysis showed that age $\geq 60$ years and TP53 mutations had adverse effect on EFS ( $P=0.015, P=0.036$, respectively) and OS $(P=0.003, P=0.004$, respectively), WBC count $\geq 50 \times 10^{\circ} / \mathrm{L}$ and FLT3-ITD negatively affected EFS ( $P=0.003, P=0.034$, respectively), whereas NPM1 mutations had favorable effect on OS $(P=0.035)$ and allogeneic hematopoietic stem cell transplantation (allo-HSCT) on EFS and OS (all $P<0.001$ ). Multivariate analysis suggested that allo-HSCT and NPM1 mutations were independent favorable prognostic factors for EFS and OS (all $P<0.05), W B C$ count $\geq 50 \times 10^{9} / L$ was an independent risk factor for EFS $(P=0.002)$ and TP53 mutations for OS $(P=0.043)$. Conclusions: Our study provided new insights into the mutational spectrum and molecular signatures of AML-M0 and M1. We proposed that FLT3-ITD, NPM1 and TP53 be identified as markers for risk stratification of AML-M0 and M1. Patients with AML-M0 and M1 would likely benefit from allo-HSCT.

\section{Introduction}

Acute myeloid leukemia (AML) is a heterogeneous malignancy characterized by clonal expansion and differentiation arrest of myeloid progenitors in the bone marrow and peripheral blood; historically AML had poor prognosis [1]. Optimizing treatment based on accurate diagnosis and prognostic evaluation in individual patients is particularly important due to disease heterogeneity [2]. Recently, next generation sequencing (NGS) has shown great potential in AML diagnosis and risk stratification because of its massive parallel sequencing ability and high throughput multiplexing capacity [3]. NGS helped characterizing several recurrent somatic mutations in AML, drawing the details of its mutational spectrum [4]. The growing list of mutations involve prognosticators such as NPM1, FLT3-ITD, CEBPA, DNMT3A, $I D H 1$ and $I D H 2$, as well as genes implicated in leukemogenesis, such as EZH2, U2AF1, SMC1A and SMC3 [5]. A recent study analyzed 1, 540 AML patients by cytogenetic profiling and targeted resequencing of 111 myeloid cancer genes, the patterns of co-occurrence and mutual exclusivities of genetic changes segregated AML patients into 11 nonoverlapping classes, each with a distinct clinical phenotype and outcome [6]. Another study analyzed the genomes of 200 adult AML patients by NGS, and mutations were divided into nine categories. Almost all AML patients had one or more mutations that fell into the nine categories, and a complex interplay of genetic alterations was found [5].

Several decades ago, in order to provide objectivity in the diagnosis of AML that would facilitate comparisons between series of cases, the French-American-British (FAB) Cooperative Group developed a classification system based on conventional morphologic and cytochemical characteristics and divided AML into FAB subtypes (M0-M7) [7], with AML-M0 and M1 being the poorly differentiated subtypes. Although advances in identification of prognostic genetic alterations have facilitated detailed risk stratification [8], currently no research has addressed the mutational spectrum of AML-M0 and M1. It's unclear whether they differ in mutational spectrum and how genetic signatures influence their prognosis. We intended to describe the clinical and molecular prognostic factors for the development of optimal and individualized therapy for AML-M0 and M1 patients.

\section{Materials and Methods}

\section{Patients}

Sixty-five AML patients derived from The Cancer Genome Atlas (TCGA) database (https:// cancergenome.nih.gov/) were enrolled in this study [5], including 19 AML-M0 and 46 AML-M1 patients. Poor-risk patients each underwent allogeneic hematopoietic stem cell transplantation (allo-HSCT) if 


\section{Cellular Physiology Cell Physiol Biochem 2018;47:1853-1861 \begin{tabular}{l|l} 
and Biochemistry Published online: June 29, 2018 & $\begin{array}{l}\text { (c) } 2018 \text { The Author(s). Published by S. Karger AG, Basel } \\
\text { www.karger.com/cpb }\end{array}$ \\
\hline
\end{tabular}

there was no contraindication and a matched donor was available. Many intermediate risk patients also underwent allo-HSCT. The number of patients receiving allo-HSCT was 37 and the rest $28 \mathrm{had}$ chemotherapy only. Whole-genome sequencing was performed to depict the mutational spectrum of each patient. Clinical characteristics at diagnosis, including peripheral blood (PB) white blood cell counts (WBC), blast percentages in $\mathrm{PB}$ and bone marrow $(\mathrm{BM})$, French-American-British (FAB) subtypes and the frequencies of known recurrent genetic mutations were described. Detailed descriptions of clinical and molecular characteristics were publicly accessible from the TCGA website. Event-free survival (EFS) and overall survival (OS) were the primary endpoints of this study. EFS was defined as the time from diagnosis to the first event including relapse, death, absence of complete remission or the last follow up. OS was defined as the time from diagnosis to death from any cause or the last follow-up. All patients provided informed consent, and the study protocol was approved by the Washington University Human Studies Committee.

\section{Statistical Analysis}

The clinical and molecular characteristics of patients were summarized using descriptive statistics. Data sets were described with median and/or range. Survival was estimated using the KaplanMeier method and the log-rank test. Univariate Cox proportional hazards models were used to identify clinical and molecular variables associated with survival. Multivariate proportional hazards models were constructed for EFS and OS, using a limited backward elimination procedure. $P<0.05$ was considered statistically significant for all analyses. All statistical tests were two-sided and were performed by SPSS software 20.0 and GraphPad Prism software 5.0 .

\section{Results}

\section{Demographic and biological characteristics of the patients}

The demographic and biological characteristics of the patients were summarized in Table 1. Median age was 58 (range 18-88) years, with 31 cases older than 60. Thirtyseven cases were men. Nineteen patients were AML-M0 and 46 were AML-M1. The median WBC count at diagnosis was $19.8 \times 10^{9} / \mathrm{L}$, and in 16 cases it was $\geq 50 \times 10^{9} / \mathrm{L}$. Fortyeight patients had BM blast percentage more than $70 \%$ and 28 had PB blasts more than $70 \%$. Thirty-four patients had abnormal karyotypes. Sixty patients had intermediate or poor risk AML. Chemotherapy was differed in two patients due to old age and poor functional status. Thirtyseven patients received HSCT, of which 24 cases achieved complete remission. Forty-six patients had more than five recurrent genetic mutations. FLT3 had the highest mutation frequency $(\mathrm{n}=20,31 \%)$, followed by NPM1 $(\mathrm{n}=18,28 \%)$, DNMT3A ( $\mathrm{n}=16,25 \%), I D H 1(\mathrm{n}=14,22 \%), I D H 2 \quad(\mathrm{n}=12$, 18\%), RUNX1 (n=11,17\%) and TET2 (n=7, 11\%) (Fig. 1).
Table 1. Clinical and molecular characteristics of the patients Abbreviations: FAB, French American British; WBC, white blood cell; BM, bone marrow; PB, peripheral blood; HSCT, hematopoietic stem cell transplantation; MUD, matched unrelated donor; Allo, allogeneic; Auto, autologous

\begin{tabular}{|c|c|}
\hline Characteristics & Median (range) or N/\% \\
\hline Age (years) & $58(18-88)$ \\
\hline$<60$ & $34 / 52.3$ \\
\hline$\geq 60$ & $31 / 47.7$ \\
\hline \multicolumn{2}{|l|}{ Gender } \\
\hline Male & $37 / 56.9$ \\
\hline Female & $28 / 43.1$ \\
\hline \multicolumn{2}{|l|}{ Race } \\
\hline Caucasian & $44 / 67.7$ \\
\hline Others & $21 / 32.3$ \\
\hline \multicolumn{2}{|l|}{ FAB subtypes } \\
\hline м0 & $19 / 29.2$ \\
\hline M1 & $46 / 70.8$ \\
\hline WBC count $/ \times 10^{9} / \mathrm{L}$ & $19.8(0.7-297.4)$ \\
\hline$<50$ & $49 / 75.4$ \\
\hline$\geq 50$ & $16 / 24.6$ \\
\hline BM blasts/\% & $81(32-100)$ \\
\hline$<70$ & $17 / 26.2$ \\
\hline$\geq 70$ & $48 / 73.8$ \\
\hline PB blasts/\% & $55(0-98)$ \\
\hline$<70$ & $37 / 56.9$ \\
\hline$\geq 70$ & $28 / 43.1$ \\
\hline Karyotype & \\
\hline Normal & $30 / 46.9$ \\
\hline Abnormal & $34 / 53.1$ \\
\hline Risk & \\
\hline Good & $4 / 6.2$ \\
\hline Intermediate & $40 / 62.5$ \\
\hline Poor & $20 / 31.3$ \\
\hline Recurrent gene mutations & $6(0-12)$ \\
\hline$<5$ & $19 / 29.2$ \\
\hline$\geq 5$ & $46 / 70.8$ \\
\hline MLL-PTD & \\
\hline Positive & $4 / 6.2$ \\
\hline Negative & $61 / 93.8$ \\
\hline FLT3 & \\
\hline FLT3-ITD & $15 / 23.1$ \\
\hline FLT3-TKD & $5 / 7.7$ \\
\hline Wild type & $45 / 69.2$ \\
\hline NPM1 & \\
\hline W288 & $18 / 27.7$ \\
\hline Wild type & $47 / 72.3$ \\
\hline DNMT3A & \\
\hline R882 & $6 / 9.2$ \\
\hline Non-R882 mutations & $10 / 15.4$ \\
\hline Wild type & $49 / 75.4$ \\
\hline IDH1 & \\
\hline R132 & $14 / 21.5$ \\
\hline Wild type & $51 / 78.5$ \\
\hline IDH2 & \\
\hline R140 & $9 / 13.9$ \\
\hline R172 & $3 / 4.6$ \\
\hline Wild type & $53 / 81.5$ \\
\hline RUNX1 & \\
\hline Mutation & $11 / 16.9$ \\
\hline Wild type & $54 / 83.1$ \\
\hline TET2 & \\
\hline Mutation & $7 / 10.8$ \\
\hline Wild type & $58 / 89.2$ \\
\hline CEBPA & \\
\hline Single-mutation & $6 / 9.2$ \\
\hline Wild type & $59 / 90.8$ \\
\hline TP53 & \\
\hline Mutation & $5 / 7.7$ \\
\hline Wild type & $60 / 92.3$ \\
\hline PTPN11 & \\
\hline Mutation & $5 / 7.7$ \\
\hline Wild type & $60 / 92.3$ \\
\hline MT-CO2 & \\
\hline Mutation & $5 / 7.7$ \\
\hline Wild type & $60 / 92.3$ \\
\hline ASXL1 & \\
\hline Mutation & $5 / 7.7$ \\
\hline Wild type & $60 / 92.3$ \\
\hline NRAS & \\
\hline Mutation & $4 / 6.2$ \\
\hline Wild type & $61 / 93.8$ \\
\hline KRAS & \\
\hline Mutation & $4 / 6.2$ \\
\hline Wild type & 61/93.8 \\
\hline TTN & \\
\hline Mutation & $4 / 6.2$ \\
\hline Wild type & $61 / 93.8$ \\
\hline STAG2 & \\
\hline Mutation & $4 / 6.2$ \\
\hline Wild type & $61 / 93.8$ \\
\hline HSCT & \\
\hline MUD & $21 / 56.8$ \\
\hline Sib alb & $12 / 32.4$ \\
\hline Auto & $4 / 10.8$ \\
\hline
\end{tabular}


Fig. 1. The mutational spectrum of the patients. FLT3 had the highest mutation frequency $(n=20,31 \%)$, followed by NPM1 $(n=18,28 \%)$, DNMT3A ( $n=16,25 \%)$, IDH1 ( $n=14,22 \%)$, IDH2 $(\mathrm{n}=12,18 \%)$, RUNX1 $(\mathrm{n}=11,17 \%)$ and TET2 $(\mathrm{n}=7,11 \%)$. In addition, CEBPA, TP53, PTPN11, MT-CO2, ASXL1, NRAS, KRAS, TTN and STAG2 also had more than 5\% mutation frequency.

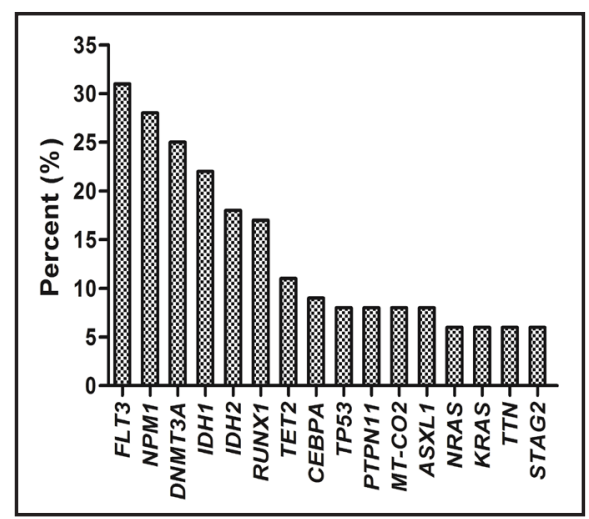

Fig. 2. Kaplan-Meier curves of EFS and OS based on clinical parameters. (A, B) Patients older than 60 years had shorter EFS and OS than those younger than 60 years. (C) Patients with WBC count $\geq 50 \times 10^{9} / \mathrm{L}$ had shorter EFS than those with WBC count $<50 \times 10^{9} / \mathrm{L}$. (D) WBC count had no effect on OS.
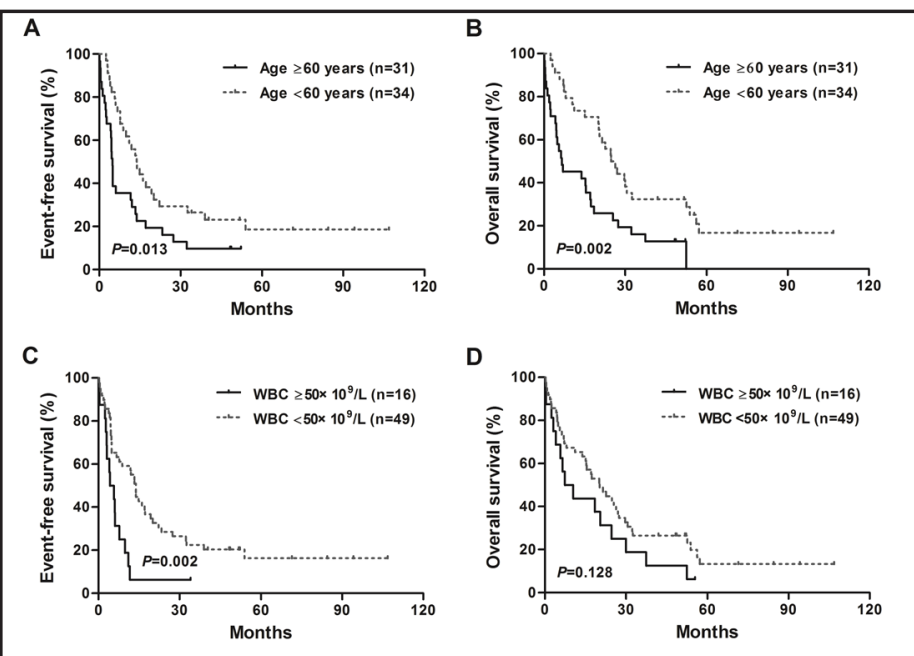

Table 2. Comparison of EFS and OS between

Comparison of EFS and OS between different clinical and molecular characteristic groups

EFS and OS of different age $(\geq 60$ vs. $<60$ years), WBC count $(\geq 50$ vs. $<50 \times 10^{9} / \mathrm{L}$ ), BM blasts ( $\geq 70 \%$ vs. $<70 \%$ ), PB blasts ( $\geq 70 \%$ vs. $<70 \%$ ), allo-HSCT (yes vs. no), FLT3-ITD (positive vs. negative), and the mutation status of other common AML mutations (NPM1, DNMT3A, IDH1, IDH2, RUNX1, CEBPA, TP53, PTPN11, MTCO2, ASXL1, NRAS, KRAS, TTN and STAG2, mutated vs. wild type), were compared with the Kaplan-Meier method and the log-rank test, as listed in Table 2. Older patients (age $\geq 60$ ) had shorter EFS and OS $(P=0.013, P=0.002$, respectively, Fig. $2 \mathrm{~A}$ and $2 \mathrm{~B})$. WBC count $\geq 50 \times 10^{9} / \mathrm{L}$ negatively affected EFS ( $P=0.002$, Fig. $2 \mathrm{C})$. Positive FLT3-ITD was associated with shorter EFS ( $P=0.031$, Fig. 3A). Patients with TP53 mutations had shorter EFS and $\mathrm{OS}(P=0.028, P=0.002$, respectively, different clinical and molecular characteristic groups. Abbreviation: EFS, event-free survival; OS, overall survival; WBC, white blood cell; BM, bone marrow; $\mathrm{PB}$, peripheral blood; Allo-HSCT, allogeneic hematopoietic stem cell transplantation

\begin{tabular}{lcccc}
\hline \multirow{2}{*}{ Variables } & \multicolumn{2}{c}{ EFS } & \multicolumn{2}{c}{ OS } \\
& $\chi^{2}$ & P-value & $\chi^{2}$ & P-value \\
\hline Age ( $\geq 60$ vs. $<60$ years) & 6.181 & 0.013 & 9.601 & 0.002 \\
WBC ( $\geq 50$ vs. $<50 \times 10^{9} / \mathrm{L}$ ) & 9.407 & 0.002 & 2.318 & 0.128 \\
BM blasts ( $\geq 70 \%$ vs. $<70 \%$ ) & 0.030 & 0.863 & 0.229 & 0.632 \\
PB blasts ( $\geq 70 \%$ vs. $<70 \%$ ) & 0.221 & 0.638 & 0.358 & 0.550 \\
FLT3-ITD (positive vs. negative) & 4.672 & 0.031 & 1.524 & 0.217 \\
NPM1 (mutated vs. wild type) & 1.594 & 0.207 & 4.609 & 0.032 \\
DNMT3A (mutated vs. wild type) & 0.003 & 0.955 & 0.611 & 0.434 \\
IDH1 (mutated vs. wild type) & 2.953 & 0.086 & 3.449 & 0.063 \\
IDH2 (mutated vs. wild type) & 0.632 & 0.427 & 0.065 & 0.798 \\
RUNX1 (mutated vs. wild type) & 1.049 & 0.306 & 3.779 & 0.052 \\
TET2 (mutated vs. wild type) & 0.070 & 0.792 & 0.017 & 0.897 \\
CEBPA (mutated vs. wild type) & 0.444 & 0.505 & 0.368 & 0.544 \\
TP53 (mutated vs. wild type) & 4.833 & 0.028 & 9.870 & 0.002 \\
PTPN11 (mutated vs. wild type) & 0.001 & 0.973 & 0.095 & 0.757 \\
MT-CO2 (mutated vs. wild type) & 0.048 & 0.827 & 0.416 & 0.519 \\
ASXL1 (mutated vs. wild type) & 0.002 & 0.960 & 0.987 & 0.321 \\
NRAS (mutated vs. wild type) & 0.006 & 0.939 & 0.009 & 0.922 \\
KRAS (mutated vs. wild type) & 0.056 & 0.814 & 0.179 & 0.673 \\
TTN (mutated vs. wild type) & 0.289 & 0.591 & 0.607 & 0.436 \\
STAG2 (mutated vs. wild type) & 0.459 & 0.498 & 1.011 & 0.315 \\
Allo-HSCT (yes vs. no) & 14.048 & $<0.001$ & 14.656 & $<0.001$ \\
\hline & & & & \\
\hline
\end{tabular}


Fig. 3. Kaplan-Meier curves of EFS and OS based on mutated genes. (A) Patients with FLT3-ITD had shorter EFS than negative group. (B) FLT3-ITD had no effect on OS. (C) NPM1 mutations had no effect on EFS. (D) Patients with NPM1 mutations had longer OS than wild type group. (E, F) Patients with TP53 mutations had shorter EFS and $\mathrm{OS}$ than wild type group.
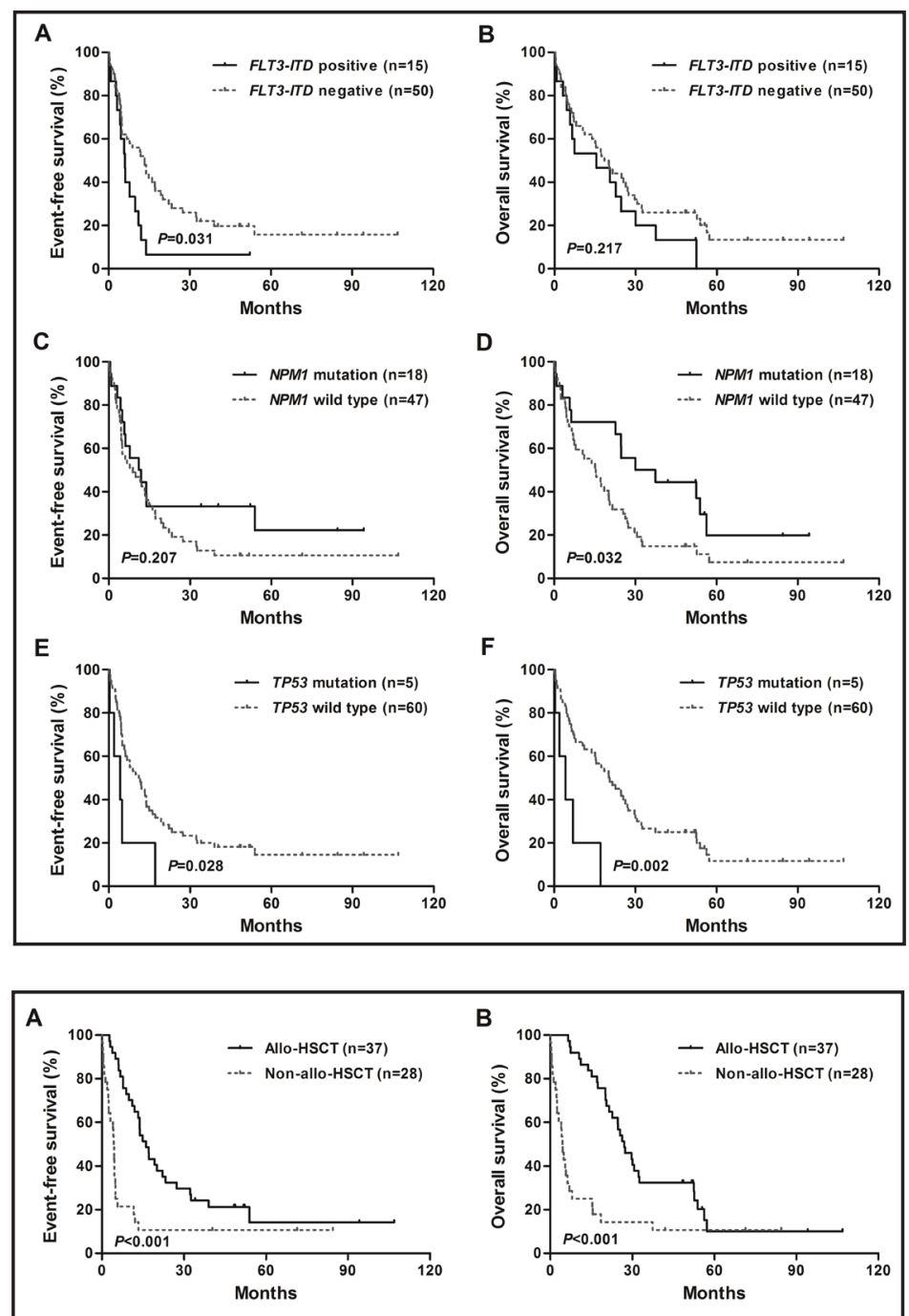

Fig. 4. Kaplan-Meier curves of EFS and os based on allo-HSCT. (A, B) Patients underwent allo-HSCT had longer EFS and OS than those without allo-HSCT.
Fig. 3E and 3F). Patients with NPM1 mutations had longer OS $(P=0.032$, Fig. 3D). Furthermore, patients received alloHSCT had longer EFS and OS $(P<0.001$, $P<0.001$, respectively, Fig. $4 \mathrm{~A}$ and $4 \mathrm{~B}$ ). Other variables did not demonstrate effect on EFS or OS.

Univariate and multivariate analyses of possible prognostic factors

To further explore the prognostic significance of the aforementioned factors, we did univariate analysis and selected factors that had statistical significance to construct the multivariate COX regression model for EFS and OS. Univariate analysis showed that age $\geq 60$ years was an unfavorable factor for EFS
Table 3. Univariate analysis for EFS and OS. Abbreviation: EFS, event-free survival; OS, overall survival; HR, hazard ratio; $\mathrm{CI}$, confidence interval; WBC, white blood cell; BM, bone marrow; $\mathrm{PB}$, peripheral blood; Allo-HSCT, allogeneic hematopoietic stem cell transplantation

\begin{tabular}{lcccc}
\hline Variables & $\begin{array}{c}\text { EFS } \\
\text { HR }(95 \% \mathrm{Cl})\end{array}$ & $\begin{array}{c}\text { P-value } \\
\text { HR (95\%CI) }\end{array}$ & P-value \\
\hline Age ( $\geq 60$ vs. $<60$ years) & $0.513(0.300-0.878)$ & 0.015 & $0.424(0.243-0.741)$ & 0.003 \\
WBC $(\geq 50$ vs. $<50 \times 109 / \mathrm{L})$ & $0.389(0.208-0.728)$ & 0.003 & $0.630(0.346-1.148)$ & 0.131 \\
BM bhsts $(\geq 70 \%$ vs. $<70 \%)$ & $0.949(0.523-1.721)$ & 0.864 & $1.156(0.637-2.098)$ & 0.633 \\
PB bhsts ( $\geq 70 \%$ vs. $<70 \%)$ & $0.879(0.513-1.506)$ & 0.639 & $1.179(0.686-2.026)$ & 0.550 \\
FLT3-ITD (positive vs. negative) & $1.967(1.051-3.684)$ & 0.034 & $1.471(0.794-2.725)$ & 0.220 \\
NPM1 (mutated vs. wild type) & $0.671(0.358-1.255)$ & 0.211 & $0.506(0.269-0.953)$ & 0.035 \\
DNMT3A (mutated vs. wild type) & $1.018(0.553-1.872)$ & 0.955 & $1.279(0.689-2.377)$ & 0.436 \\
IDH1 (mutated vs. wild type) & $0.552(0.276-1.100)$ & 0.091 & $0.525(0.263-1.048)$ & 0.068 \\
IDH2 (mutated vs. wild type) & $0.758(0.381-1.509)$ & 0.430 & $1.095(0.545-2.198)$ & 0.799 \\
RUNX1 (mutated vs. wild type) & $1.412(0.726-2.746)$ & 0.310 & $1.935(0.982-3.812)$ & 0.056 \\
TET2 (mutated vs. wild type) & $1.121(0.479-2.624)$ & 0.792 & $0.946(0.404-2.211)$ & 0.897 \\
CEBPA (mutated vs. wild type) & $1.365(0.542-3.440)$ & 0.509 & $1.330(0.527-3.356)$ & 0.546 \\
TP53 (mutated vs. wild type) & $2.727(1.070-6.951)$ & 0.036 & $4.166(1.583-10.958)$ & 0.004 \\
PTPN11 (mutated vs. wild type) & $1.016(0.404-2.556)$ & 0.973 & $1.156(0.459-2.913)$ & 0.758 \\
MT-CO2 (mutated vs. wild type) & $1.120(0.404-3.110)$ & 0.827 & $1.398(0.503-3.888)$ & 0.521 \\
ASXL1 (mutated vs. wild type) & $1.024(0.406-2.584)$ & 0.960 & $1.597(0.629-4.057)$ & 0.325 \\
NRAS (mutated vs. wild type) & $1.047(0.324-3.378)$ & 0.939 & $0.943(0.292-3.049)$ & 0.922 \\
KRAS (mutated vs. wild type) & $1.130(0.407-3.135)$ & 0.814 & $1.247(0.447-3.484)$ & 0.673 \\
TTN (mutated vs. wild type) & $1.322(0.475-3.680)$ & 0.594 & $1.503(0.535-4.222)$ & 0.439 \\
STAG2 (mutated vs. wild type) & $0.671(0.209-2.155)$ & 0.503 & $0.554(0.173-1.781)$ & 0.322 \\
Allo-HSCT (yes vs. no) & $0.365(0.211-0.631)$ & $<0.001$ & $0.358(0.208-0.618)$ & $<0.001$ \\
\hline
\end{tabular}


and OS $(P=0.015, P=0.003$, respectively), as well as TP53 mutations $(P=0.036$, $P=0.004$ for EFS and OS, respectively), WBC count $\geq 50 \times 10^{9} / \mathrm{L}$ and FLT3-ITD negatively affected EFS $(P=0.003, P=0.034$, respectively), whereas NPM1 mutations favorably affected OS $(P=0.035)$, and alloHSCT was a favorable factor for EFS and OS (all $P<0.001$ ) (Table 3). Multivariate analysis suggested that allo-HSCT was an independent favorable factor for EFS (HR: $0.358,95 \%$ CI: $0.201-0.640, P=0.001$ ), the effect was more prominent after adjusting for NPM1 mutation status $(P=0.025)$ and WBC count $(P=0.002)$. It was also an independent favorable factor for OS (HR: $0.374,95 \% \mathrm{CI}$ : $0.209-0.669, P=0.001)$, with more profound effect after adjusting for NPM1 $(P=0.002)$ and TP53 mutation status $(P=0.043)$ (Table 4$)$.

\section{Discussion}

AML is a genetically heterogeneous disease resulting from complex interactions among different leukemogenic pathways, so integrated mutational analysis is highly valuable for evaluation [5, 9]. Formerly, the mutational spectrum of AML-M0 and M1 was unclear. In this study, we found that FLT3-ITD, NPM1, DNMT3A, IDH1, IDH2, RUNX1 and TET2 were mutated in more than $10 \%$ of all patients with FLT3-ITD exhibiting the highest frequency; CEBPA, TP53, PTPN11, MT-CO2, ASXL1, NRAS, KRAS, TTN and STAG2 also had more than 5\% mutation frequency. This was different from previous reports which showed that $C E B P A$, NPM1, DNMT3A, FLT3-ITD, NRAS, IDH2 and WT1 were mutated in more than $10 \%$ and CEBPA mutations were more frequent in intermediate-risk AML $[10,11]$. The reported frequency of CEBPA mutations in cytogenetically normal AML (CN-AML) was also higher, about 35\% [12]. The discrepancy suggested that poorly differentiated AML might have a distinct mutational spectrum.

In uni- and multivariate analyses, we found that age $\geq 60$ years was an adverse factor for EFS and OS, which was consistent with the fact that AML patients younger than 60 years had improved prognosis and approximately $35-40 \%$ of them would get cured [13]. WBC count $\geq 50 \times 10^{9} / \mathrm{L}$ was also related to shorter EFS and OS, which was consistent with previous finding that WBC count had a significant impact on complete remission rate, EFS and OS in AML patients [14].

FLT3 is a class III family receptor tyrosine kinase that acts as a cytokine receptor for the FLT3 ligand. FLT3 is strongly expressed in hematopoietic stem cells with important roles in cell survival and proliferation [15]. FLT3-ITD was among the most frequent mutations observed in AML, it could activate FLT3 signaling, promoting blast proliferation [16]. Furthermore, FLT3-ITD was associated with increased risk of relapse in AML [17]. NPM1 is involved in numerous cellular functions, such as ribosome biogenesis, DNA repair and regulation of apoptosis. NPM1 mutations were among the most common genetic changes in AML, especially in CN-AML [18]. In the absence of FLT3-ITD, NPM1 mutations were associated with improved outcomes for CN-AML patients. NPM1 mutations have been associated with chemosensitivity to intensive chemotherapy in both young and old patients, which might account for improved outcomes [19]. NPM1 mutations were also associated with other recurrent genetic abnormalities, such as DNMT3A, FLT3-ITD and IDH mutations [20]. The pattern of co-mutations largely shaped clinical outcomes. TP53 mutations were rare in patients lacking chromosomal deletions, and it conferred an adverse prognosis with documented chemoresistance [21,22]. TP53 mutations might be responsible for the poor prognosis of complex karyotype AML [23]. Our results showed that FLT3-ITD and TP53 mutations were associated 
with shorter EFS and OS, while NPM1 mutations were associated with favorable prognosis, consistent with previous results. Furthermore, studies indicated that allo-HSCT could lead to better clinical outcomes for patients with unfavorable-risk cytogenetics in the first complete remission [24]. The favorable effect of allo-HSCT was also replicated in our univariate analysis, and the effect was still exist after adjusting for potential confounding factors (age, WBC, FLT3-ITD, NPM1 and TP53).

Several limitations need to be acknowledge. First, due to the limited number of our cases, we didn't stratify data more precisely based on factors that could affect the prognosis. So, our results didn't fully account for the effect of mutational spectrum and clinical data on prognosis. Second, our study was a retrospective study which could suffer from inherited biases as opposed to prospective studies.

\section{Conclusion}

In summary, we conducted a TCGA database-derived analysis on the mutational profiles and prognosis of AML-M0 and M1 and compared our findings with previous studies. Our study provided new insights into the clinical and biological implications of mutational spectrum in AML-M0 and M1. FLT3-ITD, NPM1 and TP53 could be incorporated into AML-M0 and M1 risk stratification and these patients would likely benefit from allo-HSCT.

\section{Acknowledgements}

This work was supported by grants from the National Natural Science Foundation of China $(81500118,61501519)$, the China Postdoctoral Science Foundation funded project (project No.2016M600443), Jiangsu Province Postdoctoral Science Foundation funded project (project No.1701184B) and PLAGH project of Medical Big Data (project No.2016MBD-025).

\section{Disclosure Statement}

The authors declare to have no conflict of interests.

\section{References}

1 Schlenk RF, Döhner H: Genomic applications in the clinic: use in treatment paradigm of acute myeloid leukemia. Hematology Am Soc Hematol Educ Program 2013;2013:324-330.

-2 Cazzola M, Della Porta MG, Travaglino E, Malcovati L: Classification and prognostic evaluation of myelodysplastic syndromes. Semin Oncol 2011;38:627-634.

-3 Ding L, Ley TJ, Larson DE, Miller CA, Koboldt DC, Welch JS, Ritchey JK, Young MA, Lamprecht T, McLellan MD, McMichael JF, Wallis JW, Lu C, Shen D, Harris CC, Dooling DJ, Fulton RS, Fulton LL, Chen K, Schmidt H, Kalicki-Veizer J, Magrini VJ, Cook L, McGrath SD, Vickery TL, Wendl MC, Heath S, Watson MA, Link DC, Tomasson MH, Shannon WD, Payton JE, Kulkarni S, Westervelt P, Walter MJ, Graubert TA, Mardis ER, Wilson RK, DiPersio JF: Clonal evolution in relapsed acute myeloid leukaemia revealed by wholegenome sequencing. Nature 2012;481:506-510.

4 Garraway LA: Genomics-driven oncology: framework for an emerging paradigm. J Clin Oncol 2013;31:1806-1814.

5 Ley TJ, Miller C, Ding L, Raphael BJ, Mungall AJ, Robertson A, Hoadley K, Triche TJ Jr, Laird PW, Baty JD, Fulton LL, Fulton R, Heath SE, Kalicki-Veizer J, Kandoth C, Klco JM, Koboldt DC, Kanchi KL, Kulkarni S, Lamprecht TL et al. N Engl J Med 2013;368:2059-2074. 


\section{Cellular Physiology Cell Physiol Biochem 2018;47:1853-1861

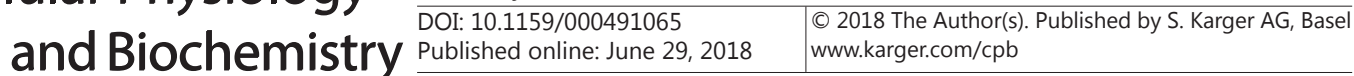

6 Papaemmanuil E, Gerstung M, Bullinger L, Gaidzik VI, Paschka P, Roberts ND, Potter NE, Heuser M, Thol F, Bolli N, Gundem G, Van Loo P, Martincorena I, Ganly P, Mudie L, McLaren S, O’Meara S, Raine K, Jones DR, Teague JW, Butler AP, Greaves MF, Ganser A, Döhner K, Schlenk RF, Döhner H, Campbell PJ: Genomic Classification and Prognosis in Acute Myeloid Leukemia. N Engl J Med 2016;374:2209-2221.

7 Bennett JM, Catovsky D, Daniel MT, Flandrin G, Galton DA, Gralnick HR, Sultan C: Proposed revised criteria for the classification of acute myeloid leukemia. A report of the French-American-British Cooperative Group. Ann Intern Med 1985;103:620-625.

8 Patel JP, Gönen M, Figueroa ME, Fernandez H, Sun Z, Racevskis J, Van Vlierberghe P, Dolgalev I, Thomas S, Aminova O, Huberman K, Cheng J, Viale A, Socci ND, Heguy A, Cherry A, Vance G, Higgins RR, Ketterling RP, Gallagher RE, Litzow M, van den Brink MR, Lazarus HM, Rowe JM, Luger S, Ferrando A, Paietta E, Tallman MS, Melnick A, Abdel-Wahab O, Levine RL: Prognostic Relevance of Integrated Genetic Profiling in Acute Myeloid Leukemia. N Engl J Med 2012;366:1079-1089.

-9 Estey EH: Acute myeloid leukemia: 2013 update on risk-stratification and management. Am J Hematol 2013;88:318-327.

10 Naoe T, Kiyoi H: Gene mutations of acute myeloid leukemia in the genome era. Int J Hematol 2013;97:165174.

11 Grossmann V, Schnittger S, Kohlmann A, Eder C, Roller A, Dicker F, Schmid C, Wendtner CM, Staib P, Serve H, Kreuzer KA, Kern W, Haferlach T, Haferlach C: A novel hierarchical prognostic model of AML solely based on molecular mutations. Blood 2012;120:2963-2972.

12 Lin LI, Chen CY, Lin DT, Tsay W, Tang JL, Yeh YC, Shen HL, Su FH, Yao M, Huang SY, Tien HF: Characterization of CEBPA mutations in acute myeloid leukemia: most patients with CEBPA mutations have biallelic mutations and show a distinct immunophenotype of the leukemic cells. Clin Cancer Res 2005;11:13721379.

13 Döhner H, Weisdorf DJ, Bloomfield CD: Acute myeloid leukemia. N Engl J Med 2015;373:1136-1152.

14 de Jonge HJ, Valk PJ, de Bont ES, Schuringa JJ, Ossenkoppele G, Vellenga E, Huls G: Prognostic impact of white blood cell count in intermediate risk acute myeloid leukemia: relevance of mutated NPM1 and FLT3ITD. Haematologica 2011;96:1310-1317.

15 Saultz JN, Garzon R: Acute Myeloid Leukemia: A Concise Review. J Clin Med 2016;5:E33.

16 Zhu GZ, Yang YL, Zhang YJ, Liu W, Li MP, Zeng WJ, Zhao XL, Chen XP: High Expression of AHSP, EPB42, GYPC and HEMGN Predicts Favorable Prognosis in FLT3-ITD-Negative Acute Myeloid Leukemia. Cell Physiol Biochem 2017;42:1973-1984.

17 Gale RE, Green C, Allen C, Mead AJ, Burnett AK, Hills RK, Linch DC: The impact of FLT3 internal tandem duplication mutant level, number, size, and interaction with NPM1 mutations in a large cohort of young adult patients with acute myeloid leukemia. Blood 2008;111:2776-2784.

18 Falini B, Nicoletti I, Martelli M F, Mecucci C: Acute myeloid leukemia carrying cytoplasmic/mutated nucleophosmin (NPMc+ AML): biologic and clinical features. Blood 2007;109:874-885.

19 Döhner K, Schlenk RF, Habdank M, Scholl C, Rücker FG, Corbacioglu A, Bullinger L, Fröhling S, Döhner H: Mutant nucleophosmin (NPM1) predicts favorable prognosis in younger adults with acute myeloid leukemia and normal cytogenetics: interaction with other gene mutations. Blood 2005;106:3740-3746.

-20 Marcucci G, Metzeler KH, Schwind S, Becker H, Maharry K, Mrózek K, Radmacher MD, Kohlschmidt J, Nicolet D, Whitman SP, Wu YZ, Powell BL, Carter TH, Kolitz JE, Wetzler M, Carroll AJ, Baer MR, Moore JO, Caligiuri MA, Larson RA, Bloomfield CD: Age-related prognostic impact of different types of DNMT3A mutations in adults with primary cytogenetically normal acute myeloid leukemia. J Clin Oncol 2012;30:742-750.

21 Haferlach C, Dicker F, Herholz H, Schnittger S, Kern W, Haferlach T: Mutations of the TP53 gene in acute myeloid leukemia are strongly associated with a complex aberrant karyotype. Leukemia 2008;22:15391541.

22 Kadia TM, Jain P, Ravandi F, Garcia-Manero G, Andreef M, Takahashi K, Borthakur G, Jabbour E, Konopleva M, Daver NG, Dinardo C, Pierce S, Kanagal-Shamanna R, Patel K, Estrov Z, Cortes J, Kantarjian HM: TP53 mutations in newly diagnosed acute myeloid leukemia: Clinicomolecular characteristics, response to therapy, and outcomes. Cancer 2016;122:3484-3491. 


\section{Cellular Physiology Cell Physiol Biochem 2018:47:1853-1861

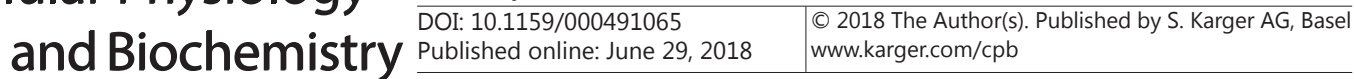 \\ Cheng et al.: Implications of Mutational Spectrum in AML-M0 and M1}

-23 Rücker FG, Schlenk RF, Bullinger L, Kayser S, Teleanu V, Kett H, Habdank M, Kugler CM, Holzmann K, Gaidzik VI, Paschka P, Held G, von Lilienfeld-Toal M, Lübbert M, Fröhling S, Zenz T, Krauter J, Schlegelberger B, Ganser A, Lichter P, Döhner K, Döhner H: TP53 alterations in acute myeloid leukemia with complex karyotype correlate with specific copy number alterations, monosomal karyotype, and dismal outcome. Blood 2012;119:2114-2121.

24 Schetelig J, Schaich M, Schäfer-Eckart K, Hänel M, Aulitzky WE, Einsele H, Schmitz N, Rösler W, Stelljes M, Baldus CD, Ho AD, Neubauer A, Serve H, Mayer J, Berdel WE, Mohr B, Oelschlägel U, Parmentier S, Röllig C, Kramer M, Platzbecker U, Illmer T, Thiede C, Bornhäuser M, Ehninger G: Hematopoietic cell transplantation in patients with intermediate and high-risk AML - results from the randomized study alliance leukemia (SAL) AML 2003 trial. Leukemia 2015;29:1060-1068. 